\title{
Erratum to: Race and Religious Participation: Introduction to Special Issue
}

\author{
Robert Joseph Taylor ${ }^{1}$ (D)
}

Published online: 30 March 2017

(c) Springer Science+Business Media New York 2017

\section{Erratum to: Race Soc Probl (2017) 9:1-3 DOI 10.1007/s12552-017-9200-6}

The original version of this article unfortunately contained a mistake in the author name of the 5th reference.
The text citation and "Reference" section should be "Henderson, L., (2017). Race discrimination, religion, and the African American drinking paradox. Race and Social Problems, 9(1), 79-90. doi:10.1007/s12552-016-9188-3".

The online version of the original article can be found under doi:10.1007/s12552-017-9200-6.

Robert Joseph Taylor

rjtaylor@umich.edu

1 Program for Research on Black Americans, School of Social Work, Institute for Social Research, University of Michigan, Ann Arbor, MI, USA 